\title{
WEBER'S LAW AND THE BIOLOGICAL EVOLUTION OF RISK PREFERENCES: THE SELECTIVE DOMINANCE OF THE LOGARITHMIC UTILITY FUNCTION
}

\author{
HANS-WERNER SINN \\ CESIFO WORKING PAPER No. 770 \\ SEPTEMBER 2002 \\ 2002 GENEVA RISK LECTURE \\ An electronic version of the paper may be downloaded \\ - from the SSRN website: www.SSRN.com \\ - from the CESifo website: www.CESifo.de \\ CATEGORY 10: EMPIRICAL AND THEORETICAL METHODS
}




\title{
WEBER'S LAW AND THE BIOLOGICAL EVOLUTION OF RISK PREFERENCES: THE SELECTIVE DOMINANCE OF THE LOGARITHMIC UTILITY FUNCTION
}

\begin{abstract}
The paper offers a proof that expected utility maximisation with logarithmic utility is a dominant preference in the biological selection process in the sense that a population following any other preference for decision-making under risk will, with a probability that approaches certainty, disappear relative to the population following this preference as time goes to infinity. The result is contrasted with Weber's and Fechner's Psychophysical Law which implies logarithmic sensation functions for objective physical stimuli.
\end{abstract}

JEL Classification: A12, D8.

Keywords: evolution, selection, risk preferences.

\author{
Hans-Werner Sinn \\ CESifo \\ (University of Munich \& Ifo Institute for \\ Economic Research) \\ Poschingerstraße 5 \\ 81679 Munich \\ Germany \\ Office@CESifo.de
}

This paper was prepared for the $29^{\text {th }}$ Seminar of the European Group of Risk and Insurance Economists, Nottingham, September 2002. I wish to thank Harris Schlesinger for useful comments to this lecture. 


\section{The Biological Roots of our Preferences}

For the methodological individualist the preferences of man are sacrosanct. They are taken as given indisputable facts on which both normative and positive theory are built. Homo oeconomicus, endowed with rational skills, acts so as to maximise his utility, given the constraints imposed by nature and markets he is facing.

However, preferences are, in fact, just a trick of nature to induce us to behave in a way that satisfies the rules of biological evolution. Evolution has produced instincts and automatic reactions that translate stimuli directly into human behaviour, but the real achievement of evolution is to endow us with intelligence, memory and preferences, thereby allowing a much more flexible and better response to whatever the constraints are that nature imposes on us.

The true preference of evolution is genetic survival and dominance, but for the purpose of efficiently directing our behaviour nature has replaced this preference with a rich body of surrogate or instrumental preferences, all too often without even revealing the trick to us. We like to rest after a long walk because we feel tired, and not in order to help our body restore its chemical and physical balance. We avoid pain because it hurts, not because we consciously want to avoid damage to our muscles, tendons, organs or joints. We like to eat because we feel hungry, not to refill our energy reservoirs, and we drink when we are thirsty, not because we have diagnosed that our blood has become too thick. We like it warm when we feel cold, and the other way around, because that gives us a pleasant feeling, not because we know that the body temperature has to stay at 37 degrees Celsius. And of course, we like to have sex when we have found an attractive partner, because this is how we feel, not because we want to reproduce our genes. In all cases we use our intelligence to find ways to satisfy our surrogate 
preferences, which basically aim at maintaining our genetic fitness and ensure reproduction, without really making us know what we are doing.

Maybe the difference between instincts and preferences is not all that large and more a matter of subjective impression than objective facts. There is a continuum in the degree of strictness in the stimulus-response relationship, from deterministic rules to a more flexible relationship that is modified by learning and reflection. And there is no fundamental distinction between animals and man - as between animals and plants only a distinction of degree. Nevertheless, economic science, which builds its theories on the assumption that rational individuals maximise their utility, should be interested in the question as to which preferences of man have been formed by evolution and why they have been formed.

There is a hierarchy of decisions in which human beings are involved and hence a hierarchy of preferences directing these decisions. Individual preferences explain the behaviour of people within firms and households. The preferences of households and firms explain the functioning of markets and political systems. National policy goals explain the outcome of systems competition. Economists have been interested in the interaction between preferences, rules of the game and final outcomes on each of these levels in the decision hierarchy, but the bottom of this hierarchy, the influence of natural selection on human preferences, has found much less attention. Encouraged by the new field of socio-biology as developed by Smith (1964), Wilson (1975), Dawkins (1976) and others, things have been changing, however. There is a growing body of economic 
literature on the biological basis of economic behaviour dealing with the issue as is summarised by Robson's (2001) recent review article. ${ }^{1}$

The instrumental preferences which steer our behaviour are not always useful. Man and his predecessors have been formed over hundreds of millions of years. They were designed and optimised by evolution for a world which was very different from the short period of cultural history of only 10,000 years or so, let alone the history since the industrial revolution. In the modern world, living conditions are so fundamentally different from all the time before that some of the preferences, which once were useful instruments helping our genes survive, no longer fulfil their original tasks. They induce a behaviour which nowadays is futile or even disadvantageous from an evolutionary perspective. Violence, overweight or sex with contraceptives are examples of this kind. Nevertheless the theory of biological evolution retains its validity as a positive explanation for why we want what we do.

Among the preferences formed by evolution, risk preferences must have been of particular importance, because rarely has there been a deterministic relationship between a man's actions and the number of offspring that could be nourished. What really happened after an economic decision depended not only on this decision, but also on the random draw of nature. In a cumbersome, and in most cases detrimental, trialand-error process, evolution must have found ways to efficiently deal with the problem of economic decision-making under risk. This is the theme of this lecture.

\footnotetext{
${ }^{1}$ There is also a growing literature in the reverse direction, introducing economic concepts to biology. See, for example, Stephens and Krebs (1986) or Kagel, Battalio and Green (1995).
} 
When making decisions, men, animals and even plants have to choose between probability distributions of resources that have direct consequences for reproduction success, and some potential decisions must have been better than others in terms of helping survival and growth of the population. It can be suspected that the blind process of genetic mutations has tried out a large many preference patterns for how to deal with the choice among probability distributions and has even found the pattern that maximised success in the natural selection process.

There are a few economic studies in the evolutionary generation of risk preferences. McAfee (1984) as well as Karni and Schmeidler (1986) derived the expected utility hypothesis from an individual's goal of maximising life expectancy and a principle of self-preservation. Assuming that individuals want to maximise the expected number of offspring, Cooper (1987) argued that evolution even respects Savage's axioms if no objective probabilities are available and Robson (1996a) showed that a concave production function for offspring implies risk aversion. ${ }^{2}$ Sinn and Weichenrieder (1993) argued that evolution selects logarithmic von NeumannMorgenstern optimisers that obey the axioms of expected utility theory, referring to the law of large numbers in a multiplicative intergenerational selection model, and this view was also adopted by Robson (1996b, 2001).

Here, I basically follow the Sinn-Weichenrieder approach, extending it by adding a proof of the evolutionary stochastic dominance of logarithmic risk preferences. $^{3}$ I also elaborate on the analogies between the Weber-Fechner law of

\footnotetext{
${ }^{2}$ Bergstrom (1997) showed that evolution can increase survival success if it randomises traits.

${ }^{3} \mathrm{I}$ had produced the proof at the time and had announced the intended publication, but time elapsed without my actually doing so. The invitation to give the plenary speech at this year's meeting of the Geneva Association was a welcome opportunity to make good on my promise, and I am grateful to
} 
psychophysics and the outcome of natural selection, a topic which I find stimulating and puzzling, without being able to give definitive answers here.

\section{Reproduction, Risk and the Goal of Evolution}

Evolution has no goals, but it follows the rules of natural selection. Traits that are inefficient die out, and only the more efficient ones remain, forming phenotypes which are better and better adapted to their environment.

It is often said that natural selection maximises fitness. It is, however, unclear what fitness really means, in particular for nature's choice of economic preferences. Fitness is a catch-all concept that has different interpretations, depending on the natural selection problem studied. To see what fitness would mean in an economic model of preference selection, consider a simple biological growth model. At time zero there are two alternative initial populations $A$ and $B$ of sizes $G_{0}^{A}$ and $G_{0}^{B}$ which, because of earlier random mutations, have different, hard-wired preferences that translate into their reproduction speed. Dependent on his choice and the deterministic state of nature (or the environment) in period $t$, a parent of type $i$, where $i=A, B$, living in period $t-1$, has the number of offspring $Q_{t}^{i}$ in period $t . Q_{t}^{i}$ is a growth factor for the population because multiplying it by the size of the old generation gives the size of the new one. Accordingly $Q_{t}^{i}-1$ is the growth rate of the population measured over a period of the 
length of one generation. After $T$ generations, the population of type $i$ will have a size of

$$
G_{T}^{i}=G_{0}^{i} \prod_{t=1}^{T} Q_{t}^{i}, i=A, B
$$

Suppose that type $A$ always has more offspring than $B$ in the sense that $Q_{t}^{B} \leq Q_{t}^{A} \cdot \gamma, \gamma=$ const. $<1, \forall t>0$. At time $T, T>0$, the size of population $B$ relative to $A$ will then satisfy the inequality

$$
\frac{G_{T}^{B}}{G_{T}^{A}}=\frac{G_{0}^{B}}{G_{0}^{A}} \prod_{t=1}^{T} \frac{Q_{t}^{B}}{Q_{t}^{A}} \leq \frac{G_{0}^{B}}{G_{0}^{A}} \gamma^{T}
$$

which obviously implies that, whatever the initial population sizes, population $B$ will vanish relative to $A$ with the passage of time:

$$
\lim _{T \rightarrow \infty} \frac{G_{T}^{B}}{G_{T}^{A}}=0
$$

Thus, in a deterministic environment, evolution will select the preference that results in a higher number of children per parent or, equivalently, a higher growth rate of the population.

Suppose now that initial mutations have produced not only two different variants of preference, resulting in two different values of the growth rate, but a sufficiently 
large variety to include the one which maximises the growth rate, given the constraints which nature is imposing. Clearly, this preference is unbeatable. With the passage of time it will become dominant over all others in terms of the number of people exhibiting it.

This has straightforward economic implications if it is assumed that the number of children a parent has is proportional to the amount of resources he commands. Suppose the parent makes a decision about where to erect his home (or nest), which territory to claim, which type of food to store or how and how much to invest in the human capital of his offspring which, one generation later, results in a particular resource flow that is available and enables the next generation to itself reach reproduction age. The resource flow available to a generation depends on both the parents' last period decision and the known state of nature. Under Malthus's law, fertility is not a limiting factor, but the resources available for the offspring determine the number of them that survive to reproduction age. It follows that men and animals would be (human and material) wealth maximisers if the environment were deterministic. The preference for maximising economic wealth, in a broader sense of the word, would be the solution to nature's problem of choosing the right preferences.

The question now is how this result can be generalised to the stochastic case. Suppose that the state of nature at time $t$ is random and that the wealth implications of the actions of a parent at time $t-1$ cannot be predicted with certainty. The result instead takes the form of a probability distribution of potential wealth levels and hence a probability distribution of the surviving number of offspring.

It is often argued that, in this case, natural selection produces the preference to maximise the probability of survival. To check this claim, assume that the growth 
factors $Q_{t}^{A}$ and $Q_{t}^{B}$ may become zero with strictly positive probabilities which then implies extinction. Let $p_{t}^{i}$ denote the transitional probability of survival of population $i$ from period $t-1$ to period $t$ and let $P_{T}^{i}$ be the probability that population $i$ is still around in period $T$, given that it exists in period 0 . Stochastic independence between the periods implies that

$$
P_{T}^{i}=\prod_{t=1}^{T} p_{t}^{i}, i=A, B
$$

Suppose population $B$ has a smaller survival probability in all periods than $A$ in the sense that $p_{t}^{B}<p_{t}^{A} \beta, \beta=$ const. $<1$. Then it is clear that the survival probability for $B$ relative to that for $A$, which satisfies the equation

$$
\frac{P_{T}^{B}}{P_{T}^{A}} \leq \beta^{T}
$$

will go to zero with the passage of time. This has only limited significance for natural selection though, for, when both $p_{t}^{B}$ and $p_{t}^{A}$ are bounded away from unity, both populations will become extinct with a probability that approximates certainty when time goes to infinity.

However, it is important to note that evolution brings about a lexicographic preference ordering between survival as such and growth in the case of survival, with no substitution possibilities between these two "goals". Suppose, in the above case, 
population $A$ has a lexicographic preference and $B$ has a substitutive preference. $A$ avoids behaviour that involves the possibility of extinction even if a high price in terms of a lower growth rate in the case of survival or even a lower expected growth rate has to be paid, but $B$ prefers a high growth rate in the lucky case of survival, accepting a certain probability of extinction: $p_{t}^{A}=1 \forall t \quad$ such that $P_{T}^{A}=1 \quad$ while $p_{t}^{B} \leq \beta, \beta=$ const. $<1$. Then, regardless of the size of this growth rate, (4) reveals that population $B$ including its particular non-lexicographic preference will become extinct with a probability that approaches unity when time goes to infinity while population $A$ survives despite its lower growth rate. This undoubtedly has an important meaning for the preferences of mankind and evolution as such. As a biologist once expressed it: survival must have been a dominant ability, because among the trillions of predecessors of a person living today, from the first cell to his own parents, there wasn't a single one that died before reproduction age.

The absence of a trade-off between the survival probability and other goals shows that nature's true problem of the choice of preferences in the stochastic case is the choice between probability distributions of wealth that exclude extinction.

Compare again two initial populations, $A$ and $B$ whose risk preferences differ due to previous mutations. The members of both populations can choose in each period from the same set of probability distributions of growth factors, but their preferences are different and thus they choose different distributions. Let $Q_{t}^{i}$ be the distribution chosen by a member of generation $t$ of population $i$ and exclude extinction by assuming that $Q_{t}^{i}>0, i=A, B$. The random variables $Q_{t}^{i}$ are stochastically independent across the generations, but perfectly correlated within the generation of a gene pool due to the 
common influence of nature. The variables may or may not be correlated across the gene pools.

By way of symmetry with the above reasoning for the case of certainty it can be suspected that natural selection will now pick a preference that leads to the maximisation of the expected growth factor $\mathrm{E} Q_{t}$ in each period and hence of the expected wealth or resource flow to endow the next generation. Suppose that $A$ always picks the highest expected value of the growth factor, while $B$ follows another criterion, which implies a lower value of the expected growth factor such that $\mathrm{E} Q_{t}^{B} \leq \gamma \mathrm{E} Q_{t}^{A}, \gamma=$ const. $<1, \forall t>0$, notwithstanding the possibility that $Q_{t}^{B}$ will take higher values than $Q_{t}^{A}$ for certain states of nature. Analogously to (1), after $T$ generations, population $i$ will have an expected size of

$$
\mathrm{E} G_{T}^{i}=G_{0}^{i} \prod_{t=1}^{T} \mathrm{E} Q_{t}^{i}, i=A, B
$$

and the expected size of population $B$ relative to that of $A$ will satisfy the inequality

$$
\frac{\mathrm{E} G_{T}^{B}}{\mathrm{E} G_{T}^{A}}=\frac{G_{0}^{B}}{G_{0}^{A}} \prod_{t=1}^{T} \frac{\mathrm{E} Q_{t}^{B}}{\mathrm{E} Q_{t}^{A}} \leq \frac{G_{0}^{B}}{G_{0}^{A}} \gamma^{T}
$$

which obviously implies that, whatever the initial population sizes, the expected value of population $B$ will vanish relative to the expected value of population $A$ with the passage of time: 


$$
\lim _{T \rightarrow \infty} \frac{\mathrm{E} G_{T}^{B}}{\mathrm{E} G_{T}^{A}}=0
$$

Thus, it seems that the analogy to the deterministic case holds. Choosing in each period the probability distribution of wealth or offspring with the higher expected value, i.e. choosing the higher expected growth rate $\mathrm{E} Q_{t}^{A}-1$, will, as time goes to infinity, lead to an expected value of the population which, relative to the size of the other population, goes beyond all bounds. Conversely, choosing always the distribution with the lower expected growth rate will imply that the relative magnitude of the expected population size will go to zero as time goes to infinity.

However, contrary to first appearances, equation (8) has little meaning for natural selection because a vanishing expected value of the relative population size is not the same as a vanishing relative population size itself. The aggregate probability distributions of population size at $T$ are extremely skewed, approaching the log-normal distribution as $T$ goes to infinity. It is possible that a distribution has a higher expected value than another one even though it has less probability mass concentrated on higher variates.

The forces of natural selection must therefore be described differently. To understand them, consider the concepts of selective quality and selective dominance. Define a preference having a higher selective quality than another one if, with a probability approximating certainty, it will lead to a higher population in the long run. And define a preference being selectively dominant if, in relation to the population path it generates, the population sizes resulting from all other (strictly different) preferences converge to zero with a probability that approximates certainty as time goes to infinity. 
Referring to the law of large numbers, Sinn and Weichenrieder (1993) argued that the maximisation of the expected logarithm of the growth factor has the highest selective quality in the above sense, and they claimed that this preference would also satisfy the criterion of selective dominance. The claim was adopted also by Robson (1996, p. 410 f.; 2001, p. 22). However, to the best of my knowledge, no one has yet delivered a proof. ${ }^{4}$

Only the proof that the maximisation of the expected logarithm of the growth factor has the highest selective quality has been given in terms of a multiperiod comparison of portfolio optimisation strategies in Sinn (1980, ch. IV B 1). Using Chebychev's inequality for the logarithms of final wealth, I showed that the maximisation of expected logarithms in each period will, with a probability that approximates certainty, indeed generate a higher final outcome than any other strategy if time goes to infinity. However that was not a proof for the strict selective dominance in the sense defined above. Will it really be true that the other preferences lead to populations sizes that vanish relative to the logarithmic expected utility strategy? This is the question to be addressed next. ${ }^{5}$

\footnotetext{
${ }^{4}$ Robson argued that selection would maximise the long-run average growth rate and he equated this growth rate to the expected short-run growth rate in the sense $\mathrm{E} \ln Q_{t}$, assuming equal probability distributions in all periods. In view of the subtle differences between the discrete average growth rate $\mathrm{E} Q_{t}-1$ and its time continuous analogue $\mathrm{E} \ln Q_{t}$ this line of argument is far from establishing a proof.

5 There is also a biological literature dealing with the optimal growth of a gene pool in a stochastic environment which uses logarithmic formulations. An extensive review of that literature is given in Sinn and Weichenrieder (1993). The analogies to the question of economic decision-making under risk as treated here are limited, though. In particular, I have been unable to find proofs of the higher selective quality, let alone the selective dominance of the expected logarithmic rule.
} 


\section{Logarithmic von Neumann-Morgenstern Utility and Selective Dominance}

The basic observation leading to the expected logarithm criterion follows from the fact that the multiplicative connection between the generations as given by (1) becomes an additive one if the logarithms of this equation are taken. In general, the logarithm of population size at time $T$ is the logarithmic sum of the original population size and the period specific growth factors:

$$
\ln G_{T}=\ln G_{0}+\sum_{t=1}^{T} \ln Q_{t}
$$

This makes it possible to apply the law of large numbers and show that the preference of maximising E $\ln Q_{t}$ will have a higher selective quality than any other preference. With a probability that approaches certainty as time goes to infinity this preference will yield a higher population size than all other rivalling preferences.

However, having the highest selective quality does not mean that other preferences will vanish from the gene pool. The proof for such an outcome is more subtle. Let $A$ denote the preference that maximises the expected logarithm of wealth and hence the expected logarithm of the number of offspring per parent in each period and let $B$ denote another preference that results in a different choice from the set of probability distributions of $Q_{t}$ available at a given point in time such that the difference in the expected logarithms is bounded away from zero, while it can be as small as we wish: 


$$
\mathrm{E} \ln Q_{t}^{A}-\mathrm{E} \ln Q_{t}^{B} \geq \gamma+\varepsilon \forall t>0, \gamma, \varepsilon=\text { const. }>0 .
$$

Moreover assume that, with the passage of time, the variance of the difference $Q_{t}^{A}-Q_{t}^{B}$ remains bounded from above in the sense that

$$
\operatorname{Var}\left(Q_{t}^{A}-Q_{t}^{B}\right) \leq \delta=\text { const. }>0 \forall t>0,
$$

which is a weak technical assumption. ${ }^{6}$ Under these conditions, preference $A$ will strictly dominate preference $B$ in natural selection.

To prove the selective dominance of preference $A$ it is sufficient to show that

$$
\lim _{T \rightarrow \infty} \mathrm{P}\left(\frac{G_{T}^{B}}{G_{T}^{A}} \geq e^{-\varepsilon T}\right)=0 .
$$

Here $\mathrm{P}(\cdot)$ denotes the probability that the size of population $B$ (the non-expected logarithm maximiser) in relation to population $A$ (the expected logarithm maximiser) remains larger than a positive quantity, $e^{-\varepsilon T}$, that shrinks indefinitely at a rate $\varepsilon$ per generation, $\varepsilon$ being the constant used in (10). Equation (12) says that this probability goes to zero with the passage of time. This is the same as saying that population $A$, which maximises the expected logarithm, will come to dominate the entire gene pool with a probability that approximates certainty as time goes to infinity. 
To prove equation (12), consider Chebyshev's inequality

$$
\mathrm{P}(|X-\mathrm{E} X| \geq \alpha) \leq \frac{\operatorname{Var} X}{\alpha^{2}}, \alpha=\text { const. }>0,
$$

where $X$ is an arbitrarily distributed random variable. This inequality implies a fortiori that

$$
\mathrm{P}(\mathrm{E} X-X \geq \alpha) \leq \frac{\operatorname{Var} X}{\alpha^{2}}
$$

Defining $\alpha \equiv \mathrm{E} X>0$, we can write Chebyshev's inequality in the form

$$
\mathrm{P}(X \leq 0) \leq \frac{\operatorname{Var} X}{\mathrm{E}^{2} X}
$$

Let $X$ denote the difference in the logarithms of population sizes at time $T$ minus a term $\varepsilon T$ which grows in proportion to time:

$$
X \equiv \sum_{t=1}^{T} \ln Q_{t}^{A}-\sum_{t=1}^{T} \ln Q_{t}^{B}+c-\varepsilon T, c \equiv \ln G_{0}^{A}-\ln G_{0}^{B}
$$

After taking expectations and using (10) it follows that

\footnotetext{
${ }^{6}$ For the proof to follow it would even suffice to assume that the variance grows less than in proportion to time, for example $\operatorname{Var}\left(Q_{t}^{A}-Q_{t}^{B}\right)<\delta T^{\beta}, \beta=$ const. $<1$, but this would be an unnecessary sophistication.
} 


$$
\mathrm{E} X \equiv \sum_{t=1}^{T} \mathrm{E} \ln Q_{t}^{A}-\sum_{t=1}^{T} \mathrm{E} \ln Q_{t}^{B}+c-\varepsilon T \geq T \gamma+c
$$

If population $B$ is initially larger than population $A, c<0$ and hence it is possible that the assumption $\mathrm{E} X>0$ is not satisfied because the term behind the inequality sign in (16) is negative. However, with the passage of time, any initial size disadvantage of population $A$ will be outperformed by the higher value of the expected logarithm population $A$ adds in every period. Thus the term behind the inequality sign will become positive in finite time:

$$
T \gamma+c>0 \text { for } T \text { sufficiently large. }
$$

It is understood in the following equations that $T$ has already become large enough to satisfy this condition. The intertemporal stochastic independence ${ }^{7}$ and (11) imply that

$$
\operatorname{Var} X=\sum_{t=1}^{T} \operatorname{Var}\left(Q_{t}^{A}-Q_{t}^{B}\right) \leq T \delta
$$

It follows from (14), (16) and (18) that

$$
P(X \leq 0) \leq \frac{T \delta}{T^{2} \gamma^{2}+c^{2}+2 T \gamma c}=\frac{\delta}{T \gamma^{2}+\frac{c^{2}}{T}+2 \gamma c}
$$

which obviously gives 


$$
\lim _{T \rightarrow \infty} P(X \leq 0)=0
$$

Now reconsider the definition of $X$ as given in (15) and transform that expression, using (9), as follows:

$$
\begin{aligned}
X & =\ln G_{T}^{A}-\ln G_{T}^{B}-\varepsilon T \\
& =\ln \frac{G_{T}^{A}}{G_{T}^{B}}-\varepsilon T \\
& =\ln \left(\frac{G_{T}^{A}}{G_{T}^{B}} e^{-\varepsilon \mathrm{T}}\right)
\end{aligned}
$$

As this implies that

$$
X \leq 0 \Leftrightarrow \frac{G_{T}^{B}}{G_{T}^{A}} \geq e^{-\varepsilon T}
$$

equation (20) is equivalent to (12). This completes the proof.

Proposition: Suppose, the maximisation of the expected logarithm of the number of offspring (and wealth) has been among the preference structures for decision-making under risk that nature has tried. Then this preference structure will, with a probability that approaches certainty, be chosen by a fraction of the aggregate population that approaches $100 \%$ as time goes to infinity.

\footnotetext{
${ }^{7}$ The variance of the sum of stochastically independent variables is the sum of their variances.
} 


\section{Interpretation}

Nature may have tried very many different preference structures with regard to decision-making under uncertainty, including rules of thumb, non-expected utility theories, expected utility approaches with different utility functions or all the other criteria which the theoretical literature on decision-making under uncertainty has brought about. If expected utility maximisation with logarithmic utility had been among the trials, it would have been the winner, allocating only vanishing fractions of the population to the rivalling preference structures.

Interestingly enough, even the preference of maximising the expected number of offspring, $\mathrm{E} Q_{t}$ or, equivalently, the expected growth rate of the population, $E Q_{t}-1$, which in the last section was shown to result in a dominant development of the expected population size, is outperformed by the logarithmic maximisation criterion. Risk neutrality in the choice of probability distributions of wealth and offspring may come relatively close to the optimum if compared to most other strategies, but even this type of preference is strictly inferior and must have disappeared relative to the best preference studied here. Risk neutrality is no dominant trait in biological evolution.

The fact that risk neutrality is inferior may look surprising if account is taken of the fact that risk choices are repeated in a similar way again and again in the process of evolution. The law of large numbers works, as has been shown. However, it does not imply a tendency towards risk neutrality as is normally the case when diversification and repetitions are possible. The reason lies in the multiplicative way risks are connected via the generations. If a generation participates in many different and stochastically independent gambles within the same period, the outcomes of these 
gambles can normally be added. The law of large numbers makes it possible to exhibit no, or only a low, degree of risk aversion in the choice of independent risks. Only the sum of all income and wealth effects enters the shape of a generation's probability distribution $Q_{t}$. The multiplicative connection between the generations makes the difference, though. It implies that a mistake that is made in one generation will reduce the population size for all times relative to what it otherwise would have been. There is no chance to recoup.

On the other hand, the chance to recoup within a generation may be even larger than a purely individual perspective would suggest. The above analysis considered risks that resulted from the randomness of nature and that applied to all individuals living at a time, at least all individuals belonging to the same gene pool. However, there may also be other risks which are more or less independent across the contemporaneous members of a gene pool. Depending on the size of the relevant population bearing the same gene, individuals can be fairly risk neutral with regard to these risks because nature can diversify across all individuals of this pool. If nature has spread the genes that steer risk taking behaviour among many individuals, there is no need for these individuals to mutually co-insure their wealth levels. What matters for the success of the gene pool is the variation in the aggregate wealth of all individuals taken together, and the variation in this aggregate can be small even if it is large for a single individual. As there is no risk aversion "in the small", an individual can be risk neutral with regard to independent risks when the gene pool is large.

This may help explain why humans and animals are willing to become "heroes" and risk their lives for the benefit of the community and why most of the idiosyncratic wealth risks of mankind remain uninsured. Biological selection imposes limitations on 
the insurance business and other risk consolidation mechanisms. People primarily seek insurance against correlated risks, but it is exactly this type of risk which is difficult to insure. True, the usual explanation for the lack of insurance markets which is based on adverse selection and asymmetric information is a powerful one. However, biological diversification across the individuals of a gene pool is an alternative, additional explanation worth discussing.

These statements are suggested interpretations, and they certainly need to be qualified insofar as an overly simplified assumption has been presented here to depict the relationship between wealth and the number of offspring. The basic result of this paper is that the maximisation of the expected logarithm of offspring is the goal of evolution. That this goal also implies a logarithmic von Neumann-Morgenstern function for wealth is a corollary based on the assumption of proportionality between wealth and the number of offspring. It is true that this assumption follows from Malthus' Law and is appropriate for a great many species. However, this law is only an approximation when the probability distributions of wealth are so widely dispersed that natural fertility may also become a constraint on the number of offspring. In this case, there will obviously be an additional reason for risk aversion which adds to the one implied by the logarithmic function. A logarithmic utility function for low and moderate wealth levels and a more strongly curved utility function for higher wealth levels results from this consideration. This is another justification for Arrow's (1971, pp. 90-120) conjecture that man's utility exhibits the property of increasing relative risk aversion with values of one for intermediate wealth levels and above one for high wealth levels. ${ }^{8}$

\footnotetext{
${ }^{8}$ A value below one for low wealth levels as conjectured by Arrow cannot be derived, though.
} 
It would be useful for future research to study the relationship between wealth and the number of offspring in more detail in order to identify further implications for risk aversion. A rich set of sophisticated models is conceivable in this regard.

A noteworthy implication of the proposition, which was already pointed out in Sinn and Weichenrieder (1993, p. 76) and which is independent of the functional relationship between wealth and the number of offspring, is that "blind" evolution may have been able to reproduce the expected utility rule as such and with it the underlying axioms: Men, animals and plants that were produced by evolution can indeed be expected to possess a rational ordering of probability distributions, to be able to assess indifference probabilities and to satisfy the much-criticised independence axiom, having consistent judgements between probability distributions before and after the results of other lottery draws have become known. Allais's paradoxes may be a matter of concern in the unnatural choice situation of the experimental laboratory, but not in real-life decision problems that are fraught with grave consequences for one's offspring.

\section{The Weber-Fechner Law}

Regardless of the necessary qualifications of the logarithmic utility function, I see a puzzling aspect of the result presented above in the kinship and similarity with Weber's law in psychophysics, sometimes also called Weber-Fechner law. In his path-breaking weight experiments Weber (1834) found that stimuli thresholds are a constant fraction of the existing stimuli. For example, he placed a weight on a person's hand and increased it gradually, asking the person to reveal when he felt the increase. The threshold weight increment turned out to be a constant fraction of the existing weight

over the normal range of weights a person would handle in everyday life. The 
experiments were repeated with other kinds of stimuli like light, sound, odours and others. Weber's law of constant relative thresholds turned out to be extremely robust.

Most of the additional experiments were carried out by Fechner (1860) who established the field of psychophysics which, in the nineteenth century, had attracted a great many scholars. Fechner interpreted the threshold as the units of subjective sensation and argued that the sensation function is logarithmic since equal relative changes in the stimuli brought about equal absolute changes in sensation. He called this the Psychophysical Law.

Fechner's interpretation has been criticised on the grounds that his reference to subjective sensation was metaphysical. One of the most intense critics was Stevens (1962, 1975), who had carried out a great number of so-called cross modality experiments, asking people to make light as bright as a sound was loud, a handgrip as tight as a light was bright and similar things. Stevens argued that, in general, the correlation he found in his cross-modality experiments could be described by power functions rather than logarithmic functions.

However, Ekman (1964) and Ekman and Sjöberg (1965) showed that Stevens's cross modality experiments were lacking an anchor that would link them to the true introspective sensation and that, in fact, they were fully compatible with underlying logarithmic sensation functions. The so-called interval measurement experiments where people were asked to increase the intensity of a physical stimulus in subjectively equal steps, uniformly supported the Psychophysical Law without contradicting Stevens's findings.

Further support for this law comes from direct neuro-physiological measurements of spike frequency in nerve fibres in relation to physical stimuli arriving 
at receptor organs. There is a rich body of literature following the seminal work of Fröhlich (1921) and Hartline and Graham (1932) which has found that, in the relevant stimulus range, the spike frequency is a logarithmic function of stimuli like light, loudness, weight, acid concentration and others.

Indeed, it seems that our perception apparatus in general is based on the relative magnitudes of signals and stimuli that we recognise. We can identify objects in bright and dim light alike, because the light intensity ratios on the retina stay constant. We perceive a melody independently of the octave in which it is played and the distance from where we hear it because the ratios of sound frequencies and loudness pressures stay constant. We drive our car at a multiple of our natural body speed without difficulties, and we live our luxurious lives with a multiple of the wealth our ancestors commanded because we perceive and react to ratios rather than absolute levels. The Weber-Fechner Law seems to be one of the fundamental constants of the way men and animals are constructed.

Even Bernoulli (1738) himself argued that the utility function of man is logarithmic when he published his famous article on the expected utility theory. To use his words: If a person ... "has a fortune worth a hundred thousand ducats and another one a fortune worth the same number of semi-ducats and if the former receives from it a yearly income of five thousand ducats while the latter obtains the same number of semiducats, it is quite clear that to the former a ducat has exactly the same signifcance as a semi-ducat to the latter..." Bernoulli had adopted the expected utility theory as such from the mathematician Cramer, and his own contribution was the logarithmic function. 
In earlier work (Sinn 1980, 1985) I criticised the argument that logarithmic introspective utility would automatically translate into logarithmic expected utility on the grounds that two people with the same function for introspective utility of deterministic wealth could still differ with regard to their risk-taking behaviour. I argued that the Weber-Fechner law would instead imply the class of constant relative risk aversion functions of which the logarithmic function is only a special case.

I must now admit that the case for a logarithmic expected utility function is stronger than I had thought since it is this function that seems to result from natural selection. Bernoulli may have been right after all and Fechner's interpretation of Weber's law may carry over to the shape of the von Neumann-Morgenstern function in a much more direct way than could have been expected.

I am not sure about the causal relationship between the selective dominance of the logarithmic expected utility function and the Weber-Fechner Law. When I first wrote about that law a quarter of a century ago, I argued that it resulted from the fact that the signals recognised by our body are encoded in relative language. Equal ratios of sound frequencies, loudness pressures and light intensities mean the same thing and require similar kinds of reaction.

I find it puzzling that the Psychophysical Law of Weber and Fechner now turns out to have the advantage of selective dominance over all other shapes of the utility function for economic decisions under uncertainty. Are there two separate reasons for the same trait of human preferences or do both reasons reflect a common deeper law of nature? This is a puzzle I have not been able to resolve. 


\section{References}

Arrow, K. (1971): Essays in the Theory of Risk Bearing, North-Holland: Amsterdam and London.

Bergstrom, Th. C. (1997): “Storage for Good Times and Bad: Of Rats and Men," UCSB working paper December 1, 1997, www.econ.ucsb.edu/ tedb/Evolution/store.pdf .

Bernoulli, D. (1738): "Specimen theoriae novae de mensura sortis," Commentarii Academiae Scientiarum Imperialis Petropolitanae 5, St. Petersburg 175-92. German translation by A. Pringsheim, Versuch einer neuen Theorie der Wertbestimmung von Glücksfällen, Duncker \& Humblot: Leipzig 1896. English translation by L. Sommer, "Exposition of a New Theory on the Measurement of Risk," Econometrica 22, 1954, 23-36.

Cooper, W. S. (1987): "Decision Theory as a Branch of Evolutionary Theory: A Biological Derivation of the Savage Axioms," Psychological Review 94, 395-411.

Dawkins, R. (1976): The Selfish Gene, Oxford University Press: New York.

Ekman, G. (1964): “Is the Power Law a Special Case of Fechner's Law?”, Perceptual and Motor Skills 19, p. 730.

Ekman, G., and L. Sjöberg (1965): “Scaling,” Annual Review of Psychology 16, 451-74.

Fröhlich, F. W. (1921): Grundzüge einer Lehre vom Licht und Farbensinn. Ein Beitrag zur allgemeinen Physiologie der Sinne, Fischer: Jena.

Fechner, G. T. (1860): Elemente der Psychophysik (two volumes), Breitkopf \& Härtel: Leipzig.

Hartling, H. K., and C. H. Graham (1932): "Nerve Impulses from Single Receptors in the Eye," Journal of Cellular and Comparative Physiology 1, 277-95.

Kagel, J. H., R. C. Battalio and L. Green (1995): Economic Choice Theory. An Experimental Analysis of Animal Behaviour, Cambridge University Press: Cambridge, UK.

Karni, E., and D. Schmeidler (1986): "Self-preservation as a Foundation of Rational Behavior under Risk," Journal of Economic Behavior and Organization 7, 71-81. 
McAfee, P. (1984): “The Nature of Risk Aversion," Mimeo, University of Western Ontario.

Robson, A. J. (1996): “A Biological Basis for Expected and Non-expected Utility," Journal of Economic Theory 68, 397-424.

--- (2001): “The Biological Basis of Economic Behavior," Journal of Economic Literature 39, 11-33.

Sinn, H.-W. (1980): Ökonomische Entscheidungen bei Ungewißheit, Mohr (Siebeck): Tübingen. English translation: Economic Decisions under Uncertainty, NorthHolland: Amsterdam, New York and Oxford, 1983. Reprint of English translation: Physica: Heidelberg 1989.

--- (1985): "Psychophysical Laws in Risk Theory," Journal of Economic Psychology 6, 185-206.

Sinn, H.-W., and A. Weichenrieder (1993): "Biological Selection of Risk Preferences," in: Bayerische Rück, ed., Risk is a Construct. Perceptions of Risk Perception, Knesebeck: Munich, 67-83

(http://www.cesifo.de/pls/ifo app/LinkSwitch?setPage=publ-special-sinnbiologic.pdf).

Smith, J. M. (1964): “Group Selection and Kin Selection,” Nature 201, 1145-47.

Stephens, D. W., and John R. Krebs (1986): Foraging Theory, Princeton University Press: Princeton.

Stevens, S. S. (1962): “The Surprising Simplicity of Sensory Metrics," American Psychologist 17, 29-39.

--- (1975): Psychophysics. Introduction to its Perceptual, Neural, and Social Prospects, Wiley: New York et al.

Wilson, E. O. (1975): Sociobiology: The New Synthesis, Cambridge, MA.

Weber, E. H. (1834): De pulsu, resorptione, auditu et tactu. Annotationes anatomicae et physiologicae, C. F. Köhler: Leipzig. 


\section{CESifo Working Paper Series}

(for full list see $\underline{w w w . c e s i f o . d e .)}$

702 Ralph Chami and Gregory D. Hess, For Better or For Worse? State-Level Marital Formation and Risk Sharing, April 2002

703 Fredrik Andersson and Kai A. Konrad, Human Capital Investment and Globalization in Extortionary States, April 2002

704 Antonis Adam and Thomas Moutos, The Political Economy of EU Enlargement: Or, Why Japan is not a Candidate Country?, April 2002

705 Daniel Gros and Carsten Hefeker, Common Monetary Policy with Asymmetric Shocks, April 2002

706 Dirk Kiesewetter and Rainer Niemann, Neutral and Equitable Taxation of Pensions as Capital Income, April 2002

707 Robert S. Chirinko, Corporate Taxation, Capital Formation, and the Substitution Elasticity between Labor and Capital, April 2002

708 Frode Meland and Gaute Torsvik, Structural Adjustment and Endogenous Worker Recall Probabilities, April 2002

709 Rainer Niemann and Caren Sureth, Taxation under Uncertainty - Problems of Dynamic Programming and Contingent Claims Analysis in Real Option Theory, April 2002

710 Thomas Moutos and William Scarth, Technical Change and Unemployment: Policy Responses and Distributional Considerations, April 2002

711 Günther Rehme, (Re-)Distribution of Personal Incomes, Education and Economic Performance Across Countries, April 2002

712 Thorvaldur Gylfason and Gylfi Zoega, Inequality and Economic Growth: Do Natural Resources Matter?, April 2002

713 Wolfgang Leininger, Contests over Public Goods: Evolutionary Stability and the FreeRider Problem, April 2002

714 Ernst Fehr and Armin Falk, Psychological Foundations of Incentives, April 2002

715 Giorgio Brunello, Maria Laura Parisi, and Daniela Sonedda, Labor Taxes and Wages: Evidence from Italy, May 2002

716 Marta Aloi and Huw Dixon, Entry Dynamics, Capacity Utilisation and Productivity in a Dynamic Open Economy, May 2002 
717 Paolo M. Panteghini, Asymmetric Taxation under Incremental and Sequential Investment, May 2002

718 Ben J. Heijdra, Christian Keuschnigg, and Wilhelm Kohler, Eastern Enlargement of the EU: Jobs, Investment and Welfare in Present Member Countries, May 2002

719 Tapio Palokangas, The Political Economy of Collective Bargaining, May 2002

720 Gilles Saint-Paul, Some Evolutionary Foundations for Price Level Rigidity, May 2002

721 Giorgio Brunello and Daniela Sonedda, Labor Tax Progressivity, Wage Determination, and the Relative Wage Effect, May 2002

722 Eric van Damme, The Dutch UMTS-Auction, May 2002

723 Paolo M. Panteghini, Endogenous Timing and the Taxation of Discrete Investment Choices, May 2002

724 Achim Wambach, Collusion in Beauty Contests, May 2002

725 Dominique Demougin and Claude Fluet, Preponderance of Evidence, May 2002

726 Gilles Saint-Paul, Growth Effects of Non Proprietary Innovation, May 2002

727 Subir Bose, Gerhard O. Orosel, and Lise Vesterlund, Optimal Pricing and Endogenous Herding, May 2002

728 Erik Leertouwer and Jakob de Haan, How to Use Indicators for 'Corporatism' in Empirical Applications, May 2002

729 Matthias Wrede, Small States, Large Unitary States and Federations, May 2002

730 Christian Schultz, Transparency and Tacit Collusion in a Differentiated Market, May 2002

731 Volker Grossmann, Income Inequality, Voting Over the Size of Public Consumption, and Growth, May 2002

$732 \mathrm{Yu}-\mathrm{Fu}$ Chen and Michael Funke, Working Time and Employment under Uncertainty, May 2002

733 Kjell Erik Lommerud, Odd Rune Straume, and Lars Sørgard, Downstream Merger with Oligopolistic Input Suppliers, May 2002

734 Saku Aura, Does the Balance of Power Within a Family Matter? The Case of the Retirement Equity Act, May 2002

735 Sandro Brusco and Fausto Panunzi, Reallocation of Corporate Resources and Managerial Incentives in Internal Capital Markets, May 2002

736 Stefan Napel and Mika Widgrén, Strategic Power Revisited, May 2002 
737 Martin W. Cripps, Godfrey Keller, and Sven Rady, Strategic Experimentation: The Case of Poisson Bandits, May 2002

738 Pierre André Chiappori and Bernard Salanié, Testing Contract Theory: A Survey of Some Recent Work, June 2002

739 Robert J. Gary-Bobo and Sophie Larribeau, A Structural Econometric Model of Price Discrimination in the Mortgage Lending Industry, June 2002

740 Laurent Linnemer, When Backward Integration by a Dominant Firm Improves Welfare, June 2002

741 Gebhard Kirchgässner and Friedrich Schneider, On the Political Economy of Environmental Policy, June 2002

742 Christian Keuschnigg and Soren Bo Nielsen, Start-ups, Venture Capitalits, and the Capital Gains Tax, June 2002

743 Robert Fenge, Silke Uebelmesser, and Martin Werding, Second-best Properties of Implicit Social Security Taxes: Theory and Evidence, June 2002

744 Wendell Fleming and Jerome Stein, Stochastic Optimal Control, International Finance and Debt, June 2002

745 Gene M. Grossman, The Distribution of Talent and the Pattern and Consequences of International Trade, June 2002

746 Oleksiy Ivaschenko, Growth and Inequality: Evidence from Transitional Economies, June 2002

747 Burkhard Heer, Should Unemployment Benefits be Related to Previous Earnings?, July 2002

748 Bas van Aarle, Giovanni Di Bartolomeo, Jacob Engwerda, and Joseph Plasmans, Staying Together or Breaking Apart: Policy-makers' Endogenous Coalitions Formation in the European Economic and Monetary Union, July 2002

749 Hans Gersbach, Democratic Mechanisms: Double Majority Rules and Flexible Agenda Costs, July 2002

750 Bruno S. Frey and Stephan Meier, Pro-Social Behavior, Reciprocity or Both?, July 2002

751 Jonas Agell and Helge Bennmarker, Wage Policy and Endogenous Wage Rigidity: A Representative View From the Inside, July 2002

752 Edward Castronova, On Virtual Economies, July 2002

753 Rebecca M. Blank, U.S. Welfare Reform: What's Relevant for Europe?, July 2002

754 Ruslan Lukach and Joseph Plasmans, Measuring Knowledge Spillovers Using Patent Citations: Evidence from the Belgian Firm's Data, July 2002 
755 Aaron Tornell and Frank Westermann, Boom-Bust Cycles in Middle Income Countries: Facts and Explanation, July 2002

756 Jan K. Brueckner, Internalization of Airport Congestion: A Network Analysis, July 2002

757 Lawrence M. Kahn, The Impact of Wage-Setting Institutions on the Incidence of Public Employment in the OECD: 1960-98, July 2002

758 Sijbren Cnossen, Tax Policy in the European Union, August 2002

759 Chandima Mendis, External Shocks and Banking Crises in Developing Countries: Does the Exchange Rate Regime Matter?, August 2002

760 Bruno S. Frey and Lars P. Feld, Deterrence and Morale in Taxation: An Empirical Analysis, August 2002

761 Lars Calmfors and Åsa Johansson, Nominal Wage Flexibility, Wage Indexation and Monetary Union, August 2002

762 Alexander R. W. Robson and Stergios Skaperdas, Costly Enforcement of Property Rights and the Coase Theorem, August 2002

763 Horst Raff, Preferential Trade Agreements and Tax Competition for Foreign Direct Investment, August 2002

764 Alex Cukierman and V. Anton Muscatelli, Do Central Banks have Precautionary Demands for Expansions and for Price Stability? - Theory and Evidence, August 2002

765 Giovanni Peri, Knowledge Flows and Knowledge Externalities, August 2002

766 Daniel Friedman and Nirvikar Singh, Equilibrium Vengeance, August 2002

767 Sam Bucovetsky and Michael Smart, The Efficiency Consequences of Local Revenue Equalization: Tax Competition and Tax Distortions, August 2002

768 Tapio Palokangas, International Labour Market Regulation and Economic Growth with Creative Destruction, August 2002

769 Rudi Dornbusch, The New International Architecture, September 2002

770 Hans-Werner Sinn, Weber's Law and the Biological Evolution of Risk Preferences: The Selective Dominance of the Logarit hmic Utility Function, September 2002 